\title{
Severe peripartum sepsis
}

\author{
S Sriskandan \\ Professor and Honorary Consultant in Infectious Diseases, National Centre for Infection Prevention and Management, Department of \\ Infectious Diseases \& Immunity, Imperial College London, UK
}

This review is based in part on Professor Sriskandan's lecture at the James Young Simpson Bicentenary Celebrations RCPE Symposium on Maternal Medicine, in association with the Royal College of Obstetrics and Gynaecology, in Edinburgh on 2 June 20II.

ABSTRACT Despite global efforts to reduce maternal mortality, maternal deaths from bacterial sepsis have actually risen in the UK. The group A streptococcus, also known as Streptococcus pyogenes, is the leading cause of infection-related death in pregnancy and the puerperium. Many clinicians remain unaware of the risks posed to this particular group of otherwise fit, healthy patients despite the fact that $S$. pyogenes has been the leading infective cause of puerperal deaths since records began. $S$. pyogenes has a specific but unexplained predilection for the recently pregnant woman, and has an attributable mortality greater than many other invasive bacteria. Here, the epidemiology, aetiology, and management of severe peripartum sepsis are discussed, as are potential approaches to reduce risks. While fundamental changes in healthcare access can lead to dramatic reductions in maternal deaths in developing countries, an improvement in maternal sepsis deaths in the UK will require heightened awareness among both hospital and community-based clinical staff.

Correspondence to S Sriskandan, National Centre for Infection Prevention and Management, Department of Infectious Diseases \& Immunity, Imperial College London, Hammersmith Campus, Du Cane Road, London WI2 ONN, UK

tel. $+44(0) 2083833243$

e-mail s.sriskandan@imperial.ac.uk

KEYWORDS Streptococcus pyogenes, puerperal sepsis, group A streptococcus, maternal mortality

DECLARATION OF INTERESTS No conflict of interests declared.

\section{INTRODUCTION}

The United Nations Millenium Development Goals, set out in the year 2000, aspired to reduce maternal deaths by three quarters between 1990 and 2015.' The vast majority of maternal deaths occur in the developing world, where the leading causes are haemorrhage, bacterial sepsis and hypertension-related disorders, together accounting for over half of all deaths related to pregnancy. ${ }^{2}$ Although such deaths often occur in settings where hospital treatment is simply not available or accessible, many developing countries are managing to improve mortality figures, though perhaps not at the rate desired.

It is therefore surprising to note that in the UK, reductions in deaths due to bacterial infection have been hard to achieve. Indeed, the triennial Centre for Maternal and Child Enquiries (CMACE) 2006-8 report highlighted that sepsis is now the leading cause of 'direct' maternal death. ${ }^{3}$ Direct causes of maternal death include events such as haemorrhage, thromboembolic disease and preeclampsia as well as sepsis and together accounted for 4.67 deaths per 100,000 maternities in the most recent survey period. Advances in healthcare have led to impressive reductions in all other major causes of direct maternal deaths, such as those related to hypertension, thromboembolic disease and haemorrhage. Notably however, the mortality rate related to sepsis increased from 0.85 deaths per 100,000 maternities in $2003-5$ to
I.I3 deaths in 2006-8. ${ }^{3}$ Maternal deaths are of course very rare in the developed world and most such deaths result from so-called 'indirect' causes, not linked directly to the pregnancy, such as pre-existing cardiac disease, meaning that the overall maternal mortality rate in the UK is II.39 per 100,000 maternities.

The pre-eminence of sepsis as a cause of death is not simply a result of proportionate reductions in other causes; absolute numbers of deaths from sepsis have in fact risen in the last two decades. ${ }^{3}$ The major pathogen responsible for deaths is the group A streptococcus (GAS), also known as Streptococcus pyogenes. This is mirrored in other developed countries including the Netherlands., ${ }^{4,5}$ Detailed microbiological data from lower income countries is less reliable, mainly because women die out of hospital or because diagnostic bacteriology is simply not feasible. Possible reasons for the increase in deaths, aside from a diminished awareness of risk among clinicians, include natural fluctuations in the year-to-year rates of GAS infections, a predominance of hypervirulent GAS strains, or an increase in the vulnerable 'at-risk' pregnant population.

Classifications of maternal infection focus heavily on 'genital tract sepsis', misleading clinicians when assessing critically ill parturitient women, and also leading to a potential underestimate in case frequency; for this reason, the term 'peripartum sepsis' is used in this review. Lethal maternal sepsis, including childbed fever 
described over a century ago, is not restricted to the genital tract. The focus of sepsis can vary according to the stage of pregnancy and includes genital tract sepsis (which may extend from cervicitis and endometritis through to pelvic thrombophlebitis and peritonitis), urosepsis, surgical site infection, pneumonia, empyema and mastitis. ${ }^{6}$ The vast majority of sepsis cases present within 24-48 hours of delivery, abortion, or rupture of membranes. ${ }^{2}$ Importantly, many cases of GAS bacteraemia with no obvious focus of infection have been reported, as have cases of invasive GAS infection at sites distant to the genital tract; ${ }^{6}$ the clinical picture is consistent with the genital tract acting as a portal of entry. Whether a GAS-specific immune defect arises at the time of parturition is unclear, however most evidence points to a general increase in innate immune responses in order to protect the mother at the point of childbirth. ${ }^{7.8}$

\section{RISK FACTORS}

The risk factors underlying maternal sepsis are not wellunderstood. The triennial CMACE reports have provided a valuable resource, ${ }^{3}$ providing in-depth case studies of those women who die from sepsis. As the report authors acknowledge, the case studies can provide insight into only a fraction of severe maternal sepsis cases and more systematic prospective surveillance is required, examining cases of severe sepsis that do not necessarily result in death. Some of the identified risk factors clearly relate to the pre-eminence of GAS infection, such as seasonality and role of concurrent upper respiratory tract infection in the pregnant woman or close family, while others such as obesity and caesarean section may relate more to risk of endometritis and post-surgical infection ${ }^{3,5,9}$ (Table I). In developing countries, all-cause maternal deaths are associated with additional risk factors such as delivery without a trained birth assistant, distance to healthcare facility and practices of traditional birth assistants, all of which are linked to poverty, and it is hard to separate risk factors for infection-related deaths specifically, ${ }^{2,10,11}$ (Table 2). Crucially, in both high- and low-income settings however, 'failure to recognise severity' is a recurrent theme among both family, birth assistants and clinical staff., $\mathrm{A}$ UK Obstetric Surveillance System (UKOSS) study has just commenced that will prospectively collect data on all cases of severe obstetric sepsis, and hopefully will provide better understanding of the factors that underlie susceptibility in a developed nation such as the UK. ${ }^{12}$ The system operates by collection of data monthly from each obstetric unit on numbers of cases of severe sepsis, as determined by a senior clinician, followed up by a questionnaire that will identify risk factors. The system efficiently collects similar data on other rare 'near miss' obstetric and perinatal conditions which are otherwise missed if collecting data based on mortality only.
TABLE I Risk factors for maternal death from sepsis identified in developed countries

\begin{tabular}{|l|}
\hline Caesarian section (emergency) \\
\hline Prolonged rupture of membranes \\
\hline Retained products of conception \\
\hline Premature labour \\
\hline History of pelvic or other infection \\
\hline Interventions e.g. cerclage, multiple vaginal examinations \\
\hline Low income \\
\hline Obesity \\
\hline Diabetes \\
\hline Anaemia \\
\hline Recent sore throat or upper respiratory tract infection in family \\
\hline Winter months \\
\hline Migrants from developing countries \\
\hline
\end{tabular}

TABLE 2 Risk factors for maternal death identified in developing countries

\begin{tabular}{|l|}
\hline Poverty \\
\hline Young age \\
\hline First pregnancy \\
\hline Anaemia \\
\hline Home delivery without trained birth assistant \\
\hline Specified traditional birth assistant practices \\
\hline Failure to recognise severity \\
\hline Distance from healthcare facilities \\
\hline Lack of medical resources \\
\hline
\end{tabular}

TABLE 3 Bacterial causes of very severe sepsis*

\begin{tabular}{|l|l|}
\hline & $\%$ cases \\
\hline Group A streptococcus (Streptococcus pyogenes) & $>50 \%$ \\
\hline Straphylococcus aureus & $10-15 \%$ \\
\hline Streptococcus pneumoniae & $2-5 \%$ \\
\hline Clostridium spp. & $2-5 \%$ \\
\hline Escherichia coli & $20-30 \%$ \\
\hline Pseudomonas spp. & $2-10 \%$ \\
\hline Klebsiella spp. & $2-5 \%$ \\
\hline Acinetobacter spp. & $2-5 \%$ \\
\hline *Rarer causes not included. Severe sepsis only. & \\
\hline
\end{tabular}




\section{BACTERIAL AETIOLOGY}

The causes of severe lethal sepsis are well-characterised, and, as discussed, GAS is the major pathogen implicated in over half of cases resulting in deaths. The other major pathogen that has been associated with maternal deaths is Escherichia coli. ${ }^{3,5}$ These two organisms should therefore underpin the empiric choice of antibiotics in severe maternal sepsis, although as can be seen, a number of other pathogens can lead to lethal sepsis and should be considered (Table 3). Some of these cases may be accompanied by bacteraemia, but by no means all, underlining the importance of acquiring samples from the genital tract, placenta, and any vaginal or wound discharge.

Bacteremia without obvious endometritis can be associated with a wide range of pathogens in the peripartum period. While it may present as a severe fulminant infection when caused by GAS, bacteraemia due to other organisms such as group B streptococcus and Listeria spp. may simply present as fever without the features of severe sepsis. The risks of invasive infection due to beta haemolytic streptococci (groups A and B) are particularly increased in the immediate peripartum period for reasons that are not understood, while the association with Listeria extends to earlier in pregnancy. Bacteraemia due to Staphylococcus aureus, E. coli, and anaerobes are more common following caesarean section. ${ }^{13}$ Placental separation may be the trigger for some cases of bacteraemia, especially where labour has been prolonged. ${ }^{14}$

Endometritis with or without bacteraemia may be caused by a range of both Gram-positive and Gramnegative organisms as well as anaerobes and those hard to culture such as Mycoplasma hominis, Ureaplasma spp., and Chlamydia spp. ${ }^{9}$

While many infections may involve endogenous urogenital pathogens, it is important to recognise that GAS is not a normal commensal of the urogenital tract, in contrast to group B streptococci (that are found in 20-40\% of women). Although there is some evidence that certain GAS serotypes may be increasing in prevalence as genital tract isolates, ${ }^{15}$ GAS vaginal carriage in late pregnancy is reported to occur in only $0.03 \% .^{16}$ This suggests that screening would be of little value, although detection of GAS in the genital tract of a pregnant or recently pregnant woman should be met with a low threshold for treating with antibiotics even in the absence of severe sepsis. Even in the pre-antibiotic era, at a time when GAS throat carriage and childbed fever were much more frequent than now, it was difficult to link postpartum GAS infections to antepartum vaginal carriage of GAS. Strains that gave rise to puerperal fever were rarely, if ever, present in the genital tract at the start of labour. Acquisition was strongly linked to cases of upper respiratory tract infection and nose or throat carriage in either the patient, her immediate family or birth attendants. ${ }^{17}$

\section{PRESENTATION OF SEVERE MATERNAL SEPSIS}

Recognition of severe sepsis in the peripartum period relies heavily on maintaining an element of suspicion. Importantly, critically ill postpartum patients may present to general physicians or emergency departments since early discharge from hospital is now the norm. A history of pregnancy should immediately alert clinicians to the possibility of a pregnancy-related illness. Severity of illness should be monitored from the point of presentation using a modified early obstetric warning system (MEOWS) chart, so that changes and deterioration are easily spotted. As learned from maternal deaths in recent triennia, ${ }^{3}$ women may present in a number of ways but there are certain guiding points that are highlighted below (Tables 4 and 5) and also in the guidance provided by the Surviving Sepsis campaign. ${ }^{18}$ Importantly, women who have undergone pregnancy are likely to be young and otherwise fit; the signs of severe systemic sepsis may therefore be masked until the moment of cardiovascular collapse. Group A streptococcus infection may be so severe that a woman may present with a leucopenia related to bone marrow suppression rather than a leucocytosis. As discussed earlier, a lack of evidence for frank genital tract sepsis does not exclude a diagnosis of severe systemic sepsis linked to the pregnancy. The genital tract may act as a portal of entry for some of the most lethal infections, for example, those caused by GAS, presenting most frequently as an occult bacteraemia. ${ }^{19}$ There may be no obvious focus for infection, or a distant focus, including pneumonia or necrotising fasciitis (Table 6 and Figure I). The risks of invasive GAS infection in the postpartum

\section{TABLE 4 Clinical signs of severe peripartum sepsis}

\begin{tabular}{|l|}
\hline Pyrexia or hypothermia \\
\hline Tachycardia \\
\hline Tachypnoea (respiratory rate $>20$ ) \\
\hline Diarrhoea \\
\hline Pain (variable degree, opiate required) \\
\hline Vaginal discharge/abnormal lochia \\
\hline Blanching erythema (toxic shock) \\
\hline
\end{tabular}

TABLE 5 Investigations that alert to severe sepsis

\begin{tabular}{|l|}
\hline Leucopenia or leucocytosis \\
\hline Raised C-reactive protein \\
\hline Raised lactate/low pH \\
\hline Thrombocytopenia \\
\hline Coagulopathy \\
\hline
\end{tabular}


TABLE 6 Clinical sites of infection in severe group A streptococcus peripartum infections ${ }^{6,19}$

\begin{tabular}{|l|l|}
\hline & Proportion \\
\hline Occult bacteraemia without focus & $40-50 \%$ \\
\hline Endometritis & $20-30 \%$ \\
\hline Peritonitis & $5-10 \%$ \\
\hline Septic abortion & $5-10 \%$ \\
\hline Cellulitis & $3-5 \%$ \\
\hline Necrotising fasciitis & $3-5 \%$ \\
\hline Septic arthritis & $3-5 \%$ \\
\hline Chorioamnionitis & $3-5 \%$ \\
\hline Pelvic vein thrombosis and thrombophlebitis & $1-3 \%$ \\
\hline
\end{tabular}

period appear to be markedly enhanced even if one discounts overt genital tract sepsis consistent with either a specific immune paresis or a streptococcal predilection for the recently parturitient genital tract as a portal of entry. ${ }^{20,21}$

\section{MANAGEMENT}

If a patient is suspected to have severe sepsis then antibiotic therapy must be instigated immediately, without awaiting test results, after blood cultures are taken and certainly within the first hour that the diagnosis is considered., ${ }^{3,18}$ Additional investigations that should be promptly instigated are further cultures of blood, vaginal swabs, urine, and any tissue or discharge. Full and thorough assessment must be undertaken by senior clinicians to establish if there is a likely source of infection that requires evacuation or drainage; this may involve imaging but care must be taken to stabilise the patient before undertaking investigations such as ultrasound or computed tomography (CT) scanning of the pelvis. Bedside ultrasound is sometimes the only investigation feasible for the sickest patients. Clearly some women may have retained products of conception, while others may still be pregnant. If source control can only be achieved by operative intervention then this should be pursued as soon as the patient is stable, with adequate explanation to the patient and family of the implications if delayed. Where relevant, samples for microbiological testing should be obtained from the placenta and infant.

In addition to high flow oxygen, intravenous fluids are an essential component of resuscitation, and must be administered promptly, although it is recognised that some of the sickest patients may develop pulmonary oedema due to endothelial leakage. Worsening acidosis or a persistent tachycardia indicates that the resuscitation process is inadequate; this may be because the woman is under-filled, although it is of course important to reconsider whether the antimicrobial cover and source control are adequate. Input from senior clinicians experienced in the care of critically ill patients at an early stage is essential, however difficulties in fluid management, acidosis or coagulopathy are clear indications for involvement of critical care teams. Monitoring is likely to require repeated blood tests, including blood gas measurements, as well as monitoring of urine output and central venous pressure.

The mortality of any patient who develops shock with organ dysfunction due to invasive $S$. pyogenes infection is around $40 \% .{ }^{20}$ Given that $S$. pyogenes is the single most important cause of severe sepsis in the peripartum

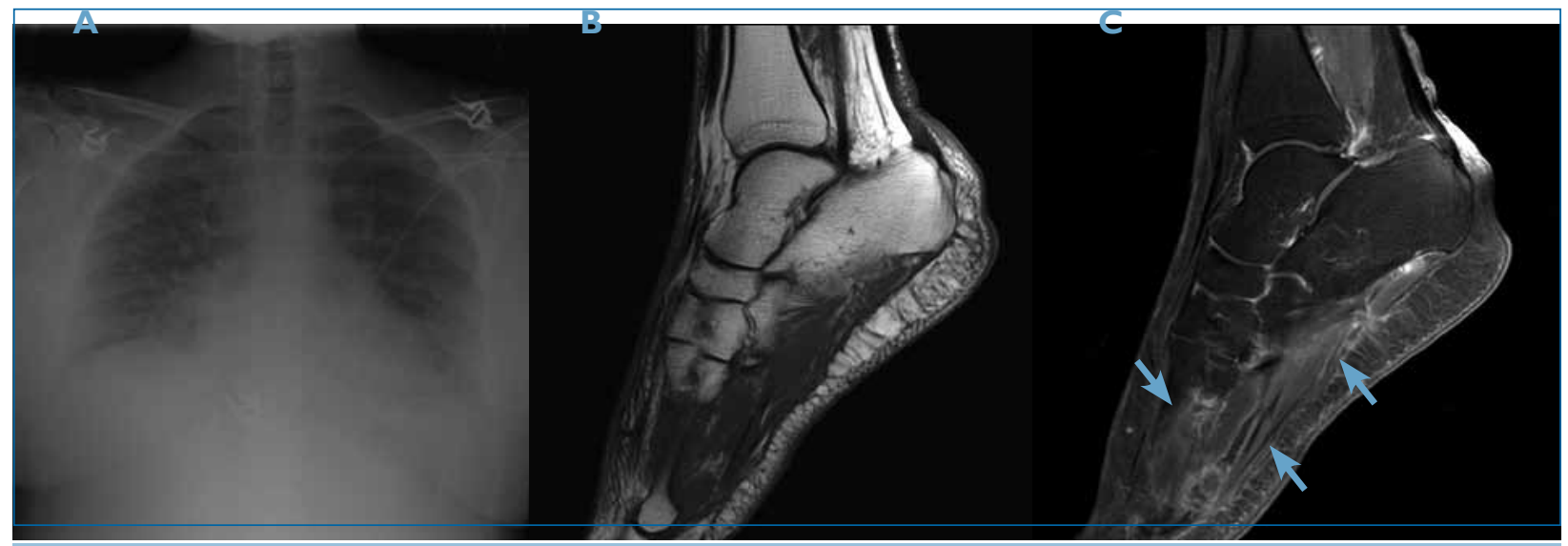

FIGURE I Peripartum streptococcal infection presenting distant from genital tract. Patient presented to her local Emergency Department six days after normal vaginal delivery of a healthy infant, complaining of flu-like illness and diarrhoea, showing signs of severe sepsis (tachycardia, 130 bpm; tachypneoa RR32/min; BP 86/50) and mottled skin. Investigations showed a coagulopathy and thrombocytopenia but a relatively normal leucocyte count. C-reactive protein was 685. Figure IA: Chest X-ray showing pulmonary congestion. The patient became increasingly hypoxic and also developed severe pain and obvious swelling of the left foot, with typical features of necrotising fasciitis, confirmed by magnetic resonance imaging. Figure IB: TI spin echo saggital image without contrast. Figure IC: TI fat saturated contrast-enhanced image showing oedematous fascial tissues (arrowed). Vaginal swabs yielded abundant group A streptococci although blood cultures were negative. Management required prolonged ICU stay and extensive debridement of the foot in addition to antimicrobial therapy. 
period, it is prudent to assume such an ominous prognosis when considering placement of the patient. This would normally be in the intensive care unit setting, or similar environment. A full discussion of severe sepsis management is beyond the scope of this article but is well-described elsewhere. ${ }^{18}$ Source control must be reconsidered once the patient is stabilised; distant seeding of GAS to cause necrotising fasciitis of soft tissues is recognised and should be dealt with as in the nonparturitient patient.

Antibiotic choice must be directed to the likeliest bacterial causes in the first instance, and can be refined once culture results are available. Senior advice should be sought from the appropriate infection team, and there are no specific trials to guide treatment. For the critically ill septic woman (who may have invasive GAS or $E$. coli infection) it is recommended that immediate intravenous therapy using a beta-lactam with anti-Gram negative action is administered, coupled with clindamycin. Clindamycin is recommended because penicillin action is impaired when growth of GAS is heavy and because clindamycin switches off bacterial toxin synthesis most effectively. ${ }^{23,24}$ The exact choice of beta-lactam will be dictated by the woman's previous microbiology results, local patterns of resistance, and history of any serious allergy. It may be reasonable to use a high dose third generation cephalosporin or piperacillin/tazobactam, although in cases where infection with an extended spectrum beta-lactamase (ESBL) producing Gramnegative organism is considered, it may be prudent to use a carbapenem. Cephalosporins will not provide adequate treatment for enterococci or Listeria however, and for this reason, some specialists prefer to avoid these agents though these organisms are less likely to be associated with severe sepsis. Most authors recommend inclusion of metronidazole in the initial regimen, although the contribution is probably minor compared with the other suggested antimicrobials. ${ }^{3}$ Where methicillin-resistant Staphylococcus aureus (MRSA) is a possibility, for example an infected surgical wound or known MRSA carriage, it is prudent to consider inclusion of a drug with appropriate activity such as teicoplanin or vancomycin initially. $A$ confirmed MRSA soft tissue infection would warrant a refinement of antimicrobial therapy.

For the less severely ill woman, initial use of a broad spectrum beta-lactam such as co-amoxyclavulanic acid is acceptable. It is important to reassess response to treatment however. A joint guideline is in development regarding management of severe sepsis related to pregnancy and this will be a valuable tool for those managing such difficult cases.

Intravenous immunoglobulin (IVIG) has been advocated for critically ill cases of suspected GAS infection that are not responding to first line therapy. Doses of $\mathrm{I}-2 \mathrm{~g} / \mathrm{kg}$ can improve bacterial clearance and neutralise circulating bacterial toxins during experimental GAS infections although there has not yet been a randomised clinical trial to support its use. ${ }^{25}$ It is rarely possible to obtain a microbiological diagnosis in this acute setting and therefore use will be based upon clinical suspicion. At present there is insufficient evidence to support use of IVIG in other types of severe sepsis affecting the recently pregnant woman.

\section{INFECTION CONTROL CONSIDERATIONS}

Care of the septic obstetric patient poses a potential cross-infection hazard highlighted by Semmelweiss in the 19th century and underpinned by Dora Colebrook's bacteriological studies of 1934. ${ }^{17}$ Given that many such cases will be infected with GAS, it is recommended that nursing and midwifery staff do not care for other women simultaneously and strict hand hygiene is required. This is best achieved through use of isolation facilities where available and standard contact precautions; a guideline has recently been produced to assist infection control teams and will be available shortly. ${ }^{26}$ As a small number of mother-baby transmission events have been noted in the past, ${ }^{15}$ it is recommended that babies born to mothers with severe sepsis are cultured and given prophylaxis whenever infection with a serious pathogen such as GAS is suspected; this does not replace existing guidance regarding group $B$ streptococcal infection.

Cases of obstetric sepsis often present following early discharge from hospital, in the community, and therefore clinicians may mistakenly exclude the possibility that a case has arisen as a result of nosocomial transmission. Vigilance is required among obstetricians and infection specialists, since linked cases may present rapidly, or several months apart, and not all cases may be associated with a sterile site isolate such as a blood culture. Cases of invasive GAS infection are now notifiable in England and Wales.

\section{MOLECULAR EPIDEMIOLOGY AND VIRULENCE FACTORS OF GAS INFECTION IN PREGNANCY}

Group A Streptococcus bacteria are classified by the structure of the bacterial surface ' $M$ ' protein that projects from the cell surface as a coiled-coil protein. Immunity to M-protein is type-specific and is believed to underpin immunity to different serotypes, of which there are over 120. The most common $M$ types causing infection of the pharynx are MI2 and M6 bacteria (Turner et al., unpublished), although the major causes of invasive infection in the UK are $\mathrm{MI}, \mathrm{M} 3$ and $M 89^{27}$ suggesting that the $\mathrm{MI}$ and $\mathrm{M} 3$ bacteria may have acquired some aspect of excessive virulence. Intriguingly, postpartum sepsis due to GAS exhibits its own molecular epidemiological patterns. For reasons that are not fully understood, M28 GAS and, to a lesser extent, M87 strains are specifically 
associated with peripartum sepsis ${ }^{28}$ (Figure 2). Analysis of the M28 GAS genome has demonstrated a so-called 'region of difference' where a number of genes appear to have similarity to the group $B$ streptococcus genome and may be involved in GAS adherence to the female genital tract. ${ }^{29}$ Despite the fact that almost one-third of cases of obstetric GAS are caused by M28 strains in Europe, deaths due to $M 28$ strains are rare. Most of the observed deaths are in women infected with $\mathrm{MI}$ or $\mathrm{M3}$ strains, again raising the possibility that these two $M$ types have excessive virulence..$^{28}$

Recent attention has focused on the role of regulatory gene mutations in the transition of GAS from harmless mucosal colonist to invasive pathogen, a feature reported most frequently among MI GAS strains. One such gene regulator controls most of the virulence factors required for defending the bacterium against neutrophil opsonophagocytosis. ${ }^{30}$ Although there is evidence that such mutations are linked to some of the most rapidly progressive sepsis cases, there is a greater number where no such mutation can be identified, at least among the isolates available to study. Importantly, all of the $M$ types that cause clinical infection carry 3-4 of the genes required for superantigen toxin synthesis, and therefore toxic shock syndrome, underpinning the importance of controlling toxin production where possible.

\section{PROSPECTS FOR PREVENTION OF PERIPARTUM SEPSIS}

In regions where maternal mortality is high, deaths due to sepsis are largely preventable. Simple interventions that address recognised risk factors are reducing mortality rates; these include ensuring a ready supply of antibiotics and trained birth attendants, coupled with removal of barriers to healthcare access. ${ }^{2}$ The impact of intrapartum vaginal biocides such as chlorhexidine wipes remains unclear; in some developing countries there was a measurable impact on maternal and neonatal health, ${ }^{31}$ while in other settings, a benefit was not detected, even where maternal sepsis rates were high. ${ }^{32}$ If GAS is acquired after childbirth, the use of intrapartum biocides may not prevent this particular infection, although one might expect an impact on other ascending infections that can cause endometritis. For caesarean section, antimicrobial prophylaxis is now widely accepted to play an important role in prevention of infection in the mother. ${ }^{33}$

The most recent CMACE report advocates education of women regarding perineal hygiene and handwashing in the period following childbirth, recognising the risk of transmission of virulent strains of GAS both in hospitals and in the home, highlighting exposure to cases of pharyngitis as a route of transmission. ${ }^{3}$ In the UK, a large proportion of women who deliver in hospital or birth centres are discharged quickly back to the home. Importantly, readmission to a maternity unit with an

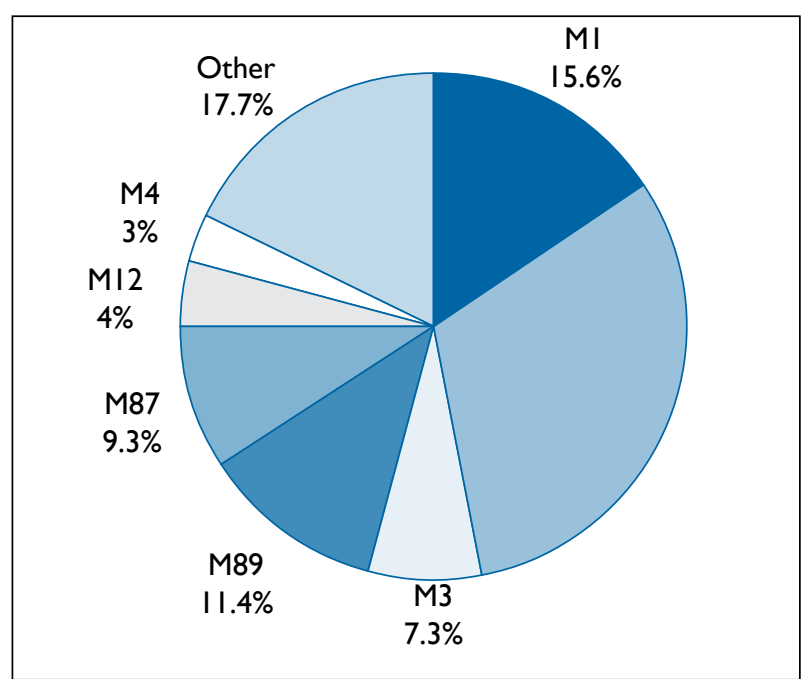

FIGURE 2 M types of a subset of S. pyogenes puerperal sepsis isolates subjected to molecular typing (2003-4). Adapted from Luca-Harari et al. ${ }^{23}$

established infection may mask the possibility that an infection could have been acquired nosocomially; vigilance is therefore required to identify increased infection rates or particular pathogens that may disclose a nosocomial outbreak. The introduction of infection control guidance for hospitals and other healthcare settings, even where just a single GAS case arises, will hopefully reduce future risk of nosocomial GAS outbreaks.

Vaccination against the main bacterial pathogen of pregnancy, GAS, remains elusive. M-protein based vaccines would need to be impossibly polyvalent to include all $M$ types worldwide ${ }^{34}$, while a vaccine targeted against the most prevalent $M$ types in the developed world may simply result in serotype replacement in the population, as has been observed for other bacterial vaccines. ${ }^{35}$ Broad spectrum immunity will require immunity to antigens that are common to all GAS; a number of these antigens have been identified and are currently being evaluated, though to date only M-proteinbased vaccines have entered clinical trials..$^{35,36}$

\section{PROSPECTS FOR PREVENTING MATERNAL DEATHS DUE TO GAS}

A dramatic reduction in maternal mortality was observed in the late 1930s in England, mainly ascribed to improved outcomes from peripartum sepsis and the introduction of antimicrobial therapy. Similar reductions in maternal deaths have been achieved in developing countries in the last decade, striving to achieve the millennium development goal set out in $2000 .^{2}$ In the specific setting of postpartum sepsis due to GAS, Leonard Colebrook achieved a remarkable 5 -fold reduction in GASassociated mortality (from $20-30 \%$ in the years $1931-5$ to $4.7 \%$ in 1936) through the introduction of sulphonamides at Queen Charlotte's Hospital. ${ }^{37}$ More than 70 years later, the overall mortality of invasive 
streptococcal disease in peripartum women has barely altered, though is thankfully much less frequent. ${ }^{20}$ This either means that we have not improved further upon standards of care since 1936, or that, despite improved care, the virulence of the infection has increased, or we have a rising at-risk population, or a combination of factors. Contemporary peripartum infections due to $\mathrm{MI}$ and M3 GAS strains are more lethal than infection with other serotypes. ${ }^{28}$ Obesity and obstetric interventions have also increased, although are unlikely alone to account for the increase in deaths due to GAS. It may be that we are limited in reducing acquisition of sporadic infection with GAS much further. Even if this were true, it should certainly be possible to prevent deaths. Failure to recognise sepsis and its severity coupled with suboptimal management have repeatedly been identified as risk factors in almost all cases of maternal death due to sepsis..$^{3,38}$ This single aspect is possibly the most important to tackle, particularly in an era where severe peripartum sepsis is rare. The introduction of education campaigns and guidelines aimed at clinical and midwifery staff, both in hospitals and in the community, as well as pregnant women will be important. This needs to be combined with proper application of diagnostic tools such as MEOWS charts and sepsis bundles, that are hard-wired to action plans, if we are to see a reduction in sepsis-related deaths.

\section{Acknowledgements}

Professor Sriskandan acknowledges the support of the Imperial College Healthcare Trust Biomedical Research Centre (BRC) and the UK CRC (National Centre for Infection Prevention and Management). Research to prevent and improve management of serious streptococcal infections has also been supported by the Conor Kerin Memorial Fund, the Lee Spark NF Foundation and the Reed Pond Walk group; the dedication and generosity of individual supporters is gratefully acknowledged.

\section{REFERENCES}

I United Nations. Millennium development goals [Internet]. New York United Nations;20 10.Available from:http://www.un.org/millenniumgoals

2 Ronsmans C, Graham WJ. Lancet maternal survival series steering group. Maternal mortality: who, when, where, and why. Lancet 2006; 368: I I89-200. http://dx.doi.org//0.I0I6/S0I40-6736(06)69380-X

3 Cantwell R, Clutton-Brock T, Cooper G. Centre for Maternal and Child Enquiries (CMACE). Saving mothers' lives: reviewing maternal deaths to make motherhood safer: 2006-08. The eighth report on confidential enquiries into maternal deaths in the United Kingdom. BJOG 201 I; I I8: I-203.

4 van Dillen J, Zwart J, Schutte J et al. Maternal sepsis: epidemiology, etiology and outcome. Curr Opin Infect Dis 20 10;23:249-54. http:// dx.doi.org/I0.1097/QCO.0b0I3e328339257c

5 Kramer HM, Schutte JM, Zwart J] et al. Maternal mortality and severe morbidity from sepsis in the Netherlands. Acta Obstet Gynecol Scand 2009; 88:647-53. http://dx.doi.org//0.1080/00016340902926734

6 Rivett LC, Williams L, Colebrook L et al. Puerperal fever. A report upon 533 cases received at the isolation block of Queen Charlotte's Hospital. Proc R Soc Med 1933; 26: I I6I-75.
7 Mason KL, Aronoff DM. Postpartum group A Streptococcus sepsis and maternal immunology. Am J Reprod Immunol 20I I. Epub ahead of print. http://dx.doi.org/I0.IIII/j.I600-0897.20II.0I083.x

8 Peltier MR. Immunology of term and preterm labor.Reprod Biol Endocrinol 2003; I:I22. http://dx.doi.org/I0. I I86/I477-7827-I-I 22

9 Maharaj D. Puerperal pyrexia:a review. Part I. Obstet Gynecol Surv 2007; 62:393-99. http://dx.doi.org//0.1097/0I.ogx.0000265998.409/2.5e

10 Gupta SD, Khanna A, Gupta R et al. Maternal mortality ratio and predictors of maternal deaths in selected desert districts in Rajasthan: a community-based survey and case control study. Womens Health Issues 2010; 20:80-85. http://dx.doi.org/I0.1016/j.whi.2009.10.003

I I Kongnyuy EJ, Mlava G, van den Broek N. Facility-based maternal death review in three districts in the central region of Malawi: an analysis of causes and characteristics of maternal deaths. Womens Health Issues 2009; 19:14-20. http://dx.doi.org/10.1016/j.whi.2008.09.008

12 UK Obstetrics Surveillance System (UKOSS). Severe maternal sepsis [Internet]. Oxford: UKOSS [cited 20II Sept 9]. Available from: https://www.npeu.ox.ac.uk/ukoss/current-surveillance/ss

I3 Kankuri E, Kurki T, Carlson $\mathrm{P}$ et al. Incidence, treatment and outcome of peripartum sepsis. Acta Obstet Gynecol Scand 2003; 82:730-35. http://dx.doi.org//0.1034/j.I600-04/2.2003.00265.x

I4 Boggess KA, Watts DH, Hillier SL et al. Bacteremia shortly after placental separation during cesarean delivery. Obstet Gynecol 1996; 87:779-84. http://dx.doi.org/10.1016/0029-7844(96)00037-3

I5 Barnham MR, Weightman NC. Bacteraemic Streptococcus pyogenes infection in the peri-partum period: now a rare disease and prior carriage by the patient may be important. J Infect 200I; 43:I73-76. http://dx.doi.org/10.1053/jinf.200I.0887

16 Mead PB, Winn WC. Vaginal-rectal colonization with group A Streptococci in late pregnancy. Infect Dis Obstet Gynaecol 2000; 8: 217-19.

17 Colebrook, D. The source of infection in puerperal fever due to haemolytic streptococci. Report for the Medical Research Council. HMSO; 1935.

I8 Dellinger RP, Levy MM, Carlet JM et al. Surviving sepsis campaign: international guidelines for management of severe sepsis and septic shock. Crit Care Med 2008; 36:296-327. http://dx.doi. org/I0.I097/0I.CCM.0000298I58.12101.4I

19 Chuang I, Van Beneden C, Beall B et al. Population-based surveillance for postpartum invasive group A streptococcus infections, 1995-2000. Clin Infect Dis 2002; 35:665-70. http:// dx.doi.org//0.1086/342062

20 Lamagni T, Efstratiou A, Sriskandan S et al. Excess maternal risk of severe group A streptococcal infection. Abstract 23. XVIIIth Lancefield International Symposium on Streptococci and Streptococcal Diseases (LISSSD); 20I I Sept; Palermo, Italy.

2I Deutscher M, Lewis M, Zell ER et al. Incidence and severity of invasive Streptococcus pneumoniae, group A Streptococcus, and group B Streptococcus infections among pregnant and postpartum women. Clin Infect Dis 20I I; 53:I I4-23.

22 Lamagni TL, Darenberg J, Luca-Harari et al. Epidemiology of severe Streptococcus pyogenes disease in Europe. Clin Microbiol Infect 2008; |4:1002-9. http://dx.doi.org/I0.I I I I/j.|469-069|.2008.02076.x

23 Stevens DL, Gibbons AE, Bergstrom $R$ et al. The eagle effect revisited: efficacy of clindamycin, erythromycin, and penicillin in the treatment of streptococcal myositis. J Infect Dis 1988; 158:23-28. http://dx.doi.org//0.1093/infdis//58.I.23

24 Sriskandan S, McKee A, Hall L et al. Comparative effects of clindamycin and ampicillin on superantigenic activity of Streptococcus pyogenes. J Antimicrob Chemother 1997; 40:275-77. http://dx.doi.org//0.1093/jac/40.2.275

25 [No authors listed]. IV immunoglobulin therapy for infectious diseases. Drug Ther Bull 2010; 48:57-60. http://dx.doi.org/I0.II36/ dtb.2009.07.0032

26 Kearney J. Guidelines for prevention and control of group A Streptococcal infection in acute healthcare and maternity settings in the UK.J Infect. Forthcoming $201 \mathrm{I}$.

27 Lamagni TL, Efstratiou A, Dennis J et al. Increase in invasive group A streptococcal infections in England,Wales and Northern Ireland, 2008-9. Euro Surveill 2009; 14: pii:19110. 
28 Luca-Harari B, Darenberg J, Neal S et al. Clinical and microbiological characteristics of severe Streptococcus pyogenes disease in Europe.J Clin Microbiol 2009; 47: I 155-65. http://dx.doi.org//0.1 I 28//CCM.02/55-08

29 Zhang S, Green NM, Sitkiewicz I et al. Identification and characterization of an antigen $1 / / \mathrm{l}$ family protein produced by group $\mathrm{A}$ Streptococcus. Infect Immun 2006; 74:4200-13. http://dx.doi.org//0.I I 28//AI.00493-06

30 Sumby P, Whitney AR, Graviss EA et al. Genome-wide analysis of group $A$ streptococci reveals a mutation that modulates global phenotype and disease specificity. PLoS Pathog 2006; 2:e5. http:// dx.doi.org//0.137//journal.ppat.0020005

3I Taha TE, Biggar RJ, Broadhead RL. Effect of cleansing the birth canal with antiseptic solution on maternal and newborn morbidity and mortality in Malawi: clinical trial. BMJ 1997;315:216-19.http://dx.doi.

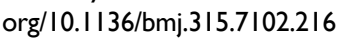

32 Rouse DJ, Cliver S, Lincoln TL et al. Clinical trial of chlorhexidine vaginal irrigation to prevent peripartal infection in nulliparous women Am J Obstet Gynecol 2003; 189:166-70. http://dx.doi.org//0.1067/ mob.2003.322

33 Smaill FM, Gyte GM. Antibiotic prophylaxis versus no prophylaxis for preventing infection after cesarean section. Cochrane Database Syst Rev 2010; I:CD007482.
34 Steer AC, Law I, Matatolu L et al. Global emm type distribution of group A streptococci: systematic review and implications for vaccine development. Lancet Infect Dis 2009; 9:611-16. http:// dx.doi.org/I0.1016/SI473-3099(09)70178-I

35 Bronze MS, Dale JB. Progress in the development of effective vaccines to prevent selected gram-positive bacterial infections. Am J Med Sci 2010; 340:2 18-25. http://dx.doi.org/I0.1097/MAJ.0b0I3e3 I8I e939ab

36 McNeil SA, Halperin SA, Langley JM et al. Safety and immunogenicity of 26-valent group $A$ streptococcus vaccine in healthy adult volunteers. Clin Infect Dis 2005; 41: I I 14-22. http://dx.doi.org//0.1086/444458

37 Colebrook L, Kenny M. Treatment with prontosil of puerperal infections due to haemolytic streptococci. Lancet 1936; 2:1319-22. http://dx.doi.org/I0.10I6/S0I40-6736(00)48I80-8

38 Lewis G, editor. The confidential enquiry into maternal and child health (CEMACH) saving mothers' lives: reviewing maternal deaths to make motherhood safer: 2003-2005. The seventh report on confidential enquiries into maternal deaths in the United Kingdom. London: CEMACH; 2007. Available at: http://www.mdeireland.com/pub/ SML07_Report.pdf

\section{UK CONSENSUS CONFERENCE APPROACHING THE COMPREHENSIVE MANAGEMENT OF ATRIAL FIBRILLATION: EVOLUTION OR REVOLUTION?

\author{
Thursday I March \& Friday 2 March 2012 \\ At the Royal College of Physicians of Edinburgh
}

This two-day UK Consensus Conference on Atrial Fibrillation has been convened by the Royal College of Physicians of Edinburgh. The key questions which the multidisciplinary panel, chaired by Dr Michael Rudolf, will aim to address from the written and oral presentations and submitted abstracts are:

- How can we best detect atrial fibrillation?

- Should the treatment of atrial fibrillation be targeted towards control of rhythm, rate or both?

- What is the most effective and safest delivery of thromboprophylaxis in atrial fibrillation?

- What are the differences between physician and patient expectation with regard to the management of atrial fibrillation?

In association with:

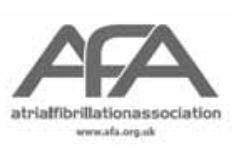

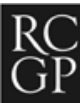

Royal College of General Practitioners
Details on registration can be obtained from: http://events.rcpe.ac.uk/ events//39/ uk-consensusconference-on-atrialfibrillation

Or by contacting: Margaret Farquhar, Consensus Conference Co-ordinator, RCPE, 9 Queen Street. Edinburgh EH2 IJQ Tel: +44 (0) I3। 2473636 E-mail:

m.farquhar@rcpe.ac.uk 